\title{
Evaluating Wind-driven Natural Ventilation Potential for Early Building Design
}

Jun Cheng, Dahai Qi, Ali Katal, Liangzhu (Leon) Wang* and Ted Stathopoulos

Centre for Zero Energy Building Studies, Department of Building, Civil and Environmental Engineering, Concordia University, Montreal, QC H3G 1M8, Canada

*Corresponding Author: Dr. Liangzhu (Leon) Wang, leon.wang@,concordia.ca 1-514-848-2424 ext. 5766

\begin{abstract}
Natural ventilation is widely applied in buildings considering its potential of improving indoor air quality and saving building energy costs. However, to evaluate its viability and determine the ventilation rates quickly and relatively accurately during early design stage is challenging. This paper explores a fast and accurate evaluation approach in the form of empirical equations to estimate the ventilation rate and potential of wind-driven natural ventilation. By using computational fluid dynamics (CFD) with results validated for both cross and single natural ventilation strategies, this study conducted a series of simulations to determine critical ventilation coefficients for the empirical equations as functions of wind direction, speed and building height. The proposed evaluation approach could help architects and engineers to evaluate the viability of natural ventilation during early building design. This approach was also demonstrated to evaluate the potential of natural ventilation in 65 cities of North America so a series of natural ventilation potential maps were generated for a better understanding of natural ventilation potential in different climates and for the climate-conscious design of buildings in North America.
\end{abstract}

Keywords: Natural ventilation potential, evaluation approach, wind-driven, early design, buildings 


\section{Nomenclature}

\begin{tabular}{|c|c|}
\hline$A$ & opening area, $\mathrm{m}^{2}$ \\
\hline$C$ & specific heat, $\mathrm{J} /\left(\mathrm{kg} \cdot{ }^{\circ} \mathrm{C}\right)$ \\
\hline$C_{D}$ & discharge coefficient \\
\hline$C_{p}$ & pressure coefficient \\
\hline$C L$ & indoor cooling load, $\mathrm{kW}$ \\
\hline$f$ & correction factor of single-sided ventilation \\
\hline$H$ & height, $\mathrm{m}$ \\
\hline$k$ & turbulence kinetic energy, $\mathrm{m}^{2} / \mathrm{s}^{2}$ \\
\hline$K$ & wind velocity coefficient \\
\hline$L$ & length, $\mathrm{m}$ \\
\hline$\dot{m}$ & mass flow rate of air, $\mathrm{kg} / \mathrm{s}$ \\
\hline$P_{a}$ & local pressure of air, $\mathrm{Pa}$ \\
\hline$P_{s}$ & local static pressure, $\mathrm{Pa}$ \\
\hline$q$ & amount of heat, $\mathrm{J}$ \\
\hline$Q$ & air flow rate, $\mathrm{m}^{3} / \mathrm{s}$ \\
\hline$t$ & time, $\mathrm{s}$ \\
\hline$T$ & temperature, ${ }^{\circ} \mathrm{C}$ \\
\hline$U$ & wind velocity, $\mathrm{m} / \mathrm{s}$ \\
\hline$U_{\tau}$ & reference wind velocity, $\mathrm{m} / \mathrm{s}$ \\
\hline$V$ & volume, $\mathrm{m}^{3}$ \\
\hline$W$ & width, m \\
\hline
\end{tabular}




\section{Greek symbols}

$\alpha$

$\gamma$

$\Delta$

$\varepsilon$

$\theta$

$\rho$

\section{Subscripts}

$i$

$O$ wind velocity coefficient

ratio of specific heat of air, 1.4 for adiabatic flows and 1.0 for isothermal flow

difference

turbulence dissipation energy, $\mathrm{m}^{2} / \mathrm{s}^{2}$

wind incidence angle, degree

density $\left(\mathrm{kg} \cdot \mathrm{m}^{-3}\right)$

indoor

outdoor 


\section{Introduction}

Natural ventilation (NV), is a process of replacing stale or noxious indoor air with fresh air without using mechanical means. NV is not a modern technique, for instance, ancient Persians and Egyptians used curved-roof vents and stone carvers to control the level of indoor dust for reducing the risk of getting respiratory diseases consciously by enhancing ventilation (Allard and Santamouris, 1998). Yet, it has been still widely applied to providing acceptable indoor air quality (IAQ) and thermal comfort when the quality of the outdoor air is suitable for NV. Multi-directional wind tower, an important application of NV, was found capable of supplying the recommended air supply rates of $10 \mathrm{~L} / \mathrm{s}$ per person for small classroom of 15 people at outdoor wind speed as low as $2 \mathrm{~m} / \mathrm{s}$ (Calautit and Hughes, 2014). Comparing to a HVAC system, NV could significantly reduce the risk of sick building syndrome (SBS) in buildings (Seppänen and Fisk, 2002). In Italian naturally ventilated classrooms, researchers found the indoor $\mathrm{CO}_{2}$ concentration could be reduced significantly especially in non-heating seasons (Stabile et al., 2016). However, when the outdoor air carries such containments as total volatile organic compounds (TVOC) and particulate matters (PM10 and PM2.5), indoor air quality (Gusten and Strindehag, 1995) and human health (Cao et al., 2017) could be affected negatively when bringing the outdoor air indoors. The situation has become quite severe, especially during winter seasons in Northern China, where the use of NV is significantly reduced due to ambient air pollution (Tong et al., 2016) mainly caused by an enormous coal consumption for power generation in this area (Chan and Yao, 2008). Even in warm/hot climates in China, Lee and Chang (2000) investigated the IAQ of five classrooms with both mechanical and natural ventilation cooling in Hong Kong. It was found that the average respirable particulate matter concentrations were higher than Hong Kong regulations. NV rate through a building also affects the airflow pattern and consequently particle transport indoors. Zhou et al. (2017) studied the particle dispersion in a ventilated and floor-heated indoor environment by experiments and numerical simulations, and found that the number of particles deposited on the floor decreased with the increase of the ventilation inlet velocity and the floor temperature. Therefore, the interplays of multiple aspects involving NV, especially the ventilation rate, outdoor and indoor air qualities, also often associated with the ventilation rate, create a quite complicated situation. Whether NV is beneficial or not seems still to be an open and case-by-case question in different situations, especially in Eastern Asian regions. 
On the other hand, the benefit of natural ventilation as a sustainable and energy saving solution seems more widely accepted in both residential and commercial building sections. In Mexico, NV was accredited with an estimated saving of $4.8 \mathrm{TWh} /$ year (Oropeza-Perez and Østergaard, 2014). In an Andalusian school, by simply replacing of the mechanical ventilation system with a NV system, it saves approximate $18-33 \%$ of annual energy consumption while maintaining classroom comfort levels (Gil-Baez et al., 2017). Meanwhile, the energy saving benefits of NV may not always ensure the required thermal comfort level when it is not well harnessed. Excessive NV rate may cool down a building and cut energy bill significantly, whereas it may cost occupant thermal comfort. Busch (1992) conducted a field study of thermal comfort in Bangkok, Thailand, based on the survey from over 1,100 office workers and simultaneous physical measurements. It was found that the upper temperature bound for natural ventilated spaces could be as high as $31^{\circ} \mathrm{C}$ for the Thai comfort standard, instead of being the currently accepted level of $26.1^{\circ} \mathrm{C}$.

In summary, a decision whether to apply NV to a building involves various considerations of outdoor/indoor air qualities, energy saving potentials and occupant thermal comfort requirements etc., for which a systematic analysis seems required. Meanwhile, before investing into a detailed engineering analysis, many decisions have to be made at the stage of early building design (i.e. conceptual design stage). For example, many key building parameters, e.g. site, shape, orientation, window-to-wall ratio (openness), internal layouts etc. are often determined at the conceptual stage, whereas they can significantly affect the NV rate and its energy saving potential. An in-depth engineering analytics, e.g. through detailed whole-building computer simulations, is simply unjustifiable and risky to be invested in terms of money and time. Therefore, it is necessary to develop a quick and relatively accurate method to evaluate NV potential through a simple strategy, such as based on a set of empirical equations, instead of a detailed engineering analysis. The method will be capable of calculating the NV rate and its energy saving potential considering building specific parameters, ambient wind aerodynamics, indoor thermal comfort and humidity levels so as to provide justifiable facts to the investors about whether a subsequent detailed engineering analysis is necessary or not.

According to opening locations, there exist two main types of NV: single-sided ventilation and cross-ventilation. In single-sided ventilation, only one façade is designed to have openings. In contrast, cross-ventilation is featured by two or more openings on adjacent or opposite façades. 
The design handbook on building natural ventilation (Allard and Santamouris, 1998) lists quite a few empirical equations regarding airflow rate estimation for both single-sided ventilation and cross-ventilation under wind. Wang and Chen (2012) developed a new empirical model that can predict the mean and fluctuating ventilation rates due to the pulsating flow and eddy penetration of single-sided, wind-driven natural ventilation of buildings. Although each of the empirical equations may apply to a specific case, they have more than one unknown parameters or coefficients that have not been identified for typical building shapes and types, and thus difficult to be generalized for early-stage NV designs. Therefore, it is necessary to develop a simple and accurate method which can be directly used for the selection of coefficients for typical and generic buildings during the early design stage.

The keystone of this study is to propose a guideline for coefficient selection based on existing equations and evaluate the natural ventilation potential for wind-driven naturally ventilated buildings with a common shape. To achieve this objective, computational fluid dynamics (CFD) is employed to determine critical ventilation coefficients as functions of wind and building information. Based on the empirical equations with the newly developed coefficients, a quick method with acceptable accuracy is developed and demonstrated to estimate the NV energy saving potentials of 65 cities of North America.

\section{Methodology}

In this section, the empirical formulas are introduced and the CFD simulation method to calculate $\mathrm{NV}$ flow rate is described. This method can be used to determine the critical ventilation coefficients in the empirical formulas. Then, based on the empirical equations, an evaluation approach will be presented to estimate the NV energy saving potential.

\subsection{Empirical formulas}

In this study, the building model is a typical modern NV building, which is assumed to be flatroofed, symmetrical, less than six floors and without any effect of internal partitions. Eqs. (1) and (2) were selected from the previous studies (Allard and Santamouris, 1998; Cockroft and Robertson, 1976), for the calculation of wind-driven single-sided ventilation and cross-ventilation flow rates, respectively. The selection was based on simplicity and better applicability compared 
to others, e.g. the equations using either constant parameters or too many unknowns were not selected.

Single-sided ventilation:

$$
Q=\frac{d v}{d t}= \pm \frac{1}{2} f C_{D} A \sqrt{\left|U^{2}-\left(\frac{2 \gamma P_{a}}{\rho V}\right) v\right|}
$$

Cross ventilation:

$$
Q=\sqrt{\frac{C p_{1}-C p_{2}}{\frac{1}{A_{1}^{2} C_{D_{1}}^{2}+\frac{1}{A_{2}^{2} C_{D_{2}}^{2}}}}} U=\sqrt{\frac{\Delta C_{p}}{\frac{1}{A_{1}^{2} C_{D_{1}}^{2}}+\frac{1}{A_{2}^{2} C_{D_{2}}^{2}}}} U
$$

where $d v$ is the decrease in volume of the original mass of air inside the building $\left(\mathrm{m}^{3}\right), V$ is total volume of the building $\left(\mathrm{m}^{3}\right), t$ is the time $(\mathrm{s}), \gamma$ is the specific heat ratio of air which equals to 1.4 for adiabatic flows and 1.0 for isothermal flows (Haghighat et al., 2000), $\rho$ is the density of air $\left(\mathrm{kg} / \mathrm{m}^{3}\right)$ and $P_{a}$ is the atmospheric pressure $(\mathrm{Pa}) . U$ is wind velocity and is calculated by Eq. (3), where the wind velocity coefficients, $K$ and $\alpha$, are for wind profile, and discharge coefficients, $C_{D}$, for window type selection are considered as constants - see Table 1 and Table 2.

$$
U=U_{r} \cdot K \cdot Z^{\alpha}
$$

Table 1. Wind velocity coefficients $K$ and $\alpha$ over different terrains (Andersen et al., 2002).

\begin{tabular}{ccc}
\hline Terrain & $\boldsymbol{K}$ & $\boldsymbol{\alpha}$ \\
\hline Open area & 0.68 & 0.17 \\
\hline Suburban area & 0.35 & 0.25 \\
\hline Urban area & 0.21 & 0.33 \\
\hline
\end{tabular}

Table 2. Discharge coefficients $C_{D}$ for different window types (Wang et al., 2012).

\begin{tabular}{cc}
\hline Window type & Discharge coefficient $\boldsymbol{C}_{\boldsymbol{D}}$ \\
\hline Casement & 0.65 \\
\hline Tilt & 0.55 \\
\hline Sliding & 0.35 \\
\hline
\end{tabular}


Besides the opening area $A\left(\mathrm{~m}^{2}\right)$ and reference wind velocity $U_{r}(\mathrm{~m} / \mathrm{s})$, there are two key undetermined coefficients $f$ and $\Delta C_{p}$ for the evaluation of airflow rates under single-sided and cross ventilation, respectively. One of the objectives of this study is to develop a guideline for the selection of the two coefficients. To achieve this, the airflow rates through the openings under different scenarios, e.g. different wind incidence angles, can be determined by CFD simulations which will be introduced in section 2.2. Then the two key coefficients $f$ and $\Delta C_{p}$ can be backcalculated using Eqs. (1) and (2) with the CFD-calculated airflow rates. $f$ and $\Delta C_{p}$ are then correlated as the function of wind direction, as will be demonstrated by a case study in section 3.2.

For a given internal cooling load defined by, $C L(\mathrm{~kW})$, the resultant indoor air temperature $T_{i}$, could be obtained by:

$$
T_{i}=\frac{C L}{\dot{\mathrm{m} C}}+T_{o}
$$

where $\dot{m}$ is the mass flow rate from the $\mathrm{NV}(\mathrm{kg} / \mathrm{s}), C$ is the specific heat of air $\left(\mathrm{kJ} / \mathrm{kg} \cdot{ }^{\circ} \mathrm{C}\right)$ and $T_{o}$ is the outdoor air temperature $\left({ }^{\circ} \mathrm{C}\right)$.

The annual NV energy saving potential is quantified by the total number of hours in a year when the resultant indoor air temperature $T_{i}$ and outdoor air relative humidity $(R H)$ falls within the defined acceptable ranges for the occupants of the building (Eqs. 5 and 6). The more annual NV available hours indicate more annual NV potential and therefore more potential of energy saving. Section 2.3 shows the evaluation approach using the empirical equations.

Using hourly weather data as an example, under NV and at a certain hourly weather condition, when the indoor air temperature, $T_{i}$, and outdoor air relative humidity $(R H)$ satisfy the conditions in Eqs. 5 and 6, the hour is then counted towards the total NV energy saving potential hours for a given indoor heat gain $(C L, \mathrm{~kW})$ :

$$
\begin{array}{lr}
21.5^{\circ} \mathrm{C} \leq T_{i} \leq 27.8^{\circ} \mathrm{C} & (\text { ASHRAE, 2004) } \\
20 \% \leq \mathrm{RH} \leq 70 \% & (\text { Collins, 1986) }
\end{array}
$$




\subsection{CFD simulation}

To calculate the NV airflow rate through the generic buildings, CFD simulations, which have been proven to be an effective method to simulate building ventilation (Deng et al., 2017; Tominaga and Stathopoulos, 2011), were carried out. Calautit and Hughes (2014) conducted CFD simulations with the standard k- $\varepsilon$ turbulence model, then compared to the wind tunnel test results based on various wind speeds and incidence angles and found a difference less than $20 \%$ between simulations and measurements. Ai and Mak (2018) investigated single-sided NV in buildings in urban areas by conducting CFD simulations for room ventilation rate analysis. It has been shown that the ventilation rate would be decreased up to $67 \%$ when the aspect ratio of a street canyon is significantly increased. Cheung and Liu (2011) explored the effects of building interference on $\mathrm{NV}$ using the standard two-equation $\mathrm{k}-\varepsilon$ model. The cross ventilation rate could be doubled by a proper building disposition for improving NV performance.

In this study, the CFD models of the generic buildings were developed. As illustrated in Fig. 1, an example of the four-story building $80 \mathrm{~m} \times 25 \mathrm{~m} \times 14.4 \mathrm{~m}(\mathrm{~L} \times \mathrm{W} \times \mathrm{H})$ placed within a larger computational domain, which has an upstream length of $4 \mathrm{~W}$, a lateral length of $4 \mathrm{~L}$ on both sides and a vertical length of $4 \mathrm{H}$ above the building height as Jiang et al. (2003) suggested in their research; except, instead of $8 \mathrm{~W}$ there is a slightly shorter downstream length of $6 \mathrm{~W}$ in this study to reduce computational time. The building has uniformly distributed thirty-two windows on each long side (depending on ventilation strategy). With the consideration of the balance between energy-saving and daylighting requirements, the window-to-wall ratio (WWR) is set to be $30 \%$ in the model (Dubois and Blomsterberg, 2011; Tzempelikos and Athienitis, 2007). The CFD models were created in ANSYS FLUENT 16.2 and the "CutCell" method was applied for the meshing assembly. Approximately 500,000 meshes were generated with a minimum size of $0.3 \mathrm{~m}$. A steady-state Reynolds-Averaged Navier-Stokes (RANS) standard $k-\varepsilon$ turbulence model was used. To investigate the grid independence, two incidence angles $\theta$ of $45^{\circ}$ and $90^{\circ}$ with almost three times of the total meshes were used in the same model to compare the airflow rates for both singlesided and cross-ventilation. 


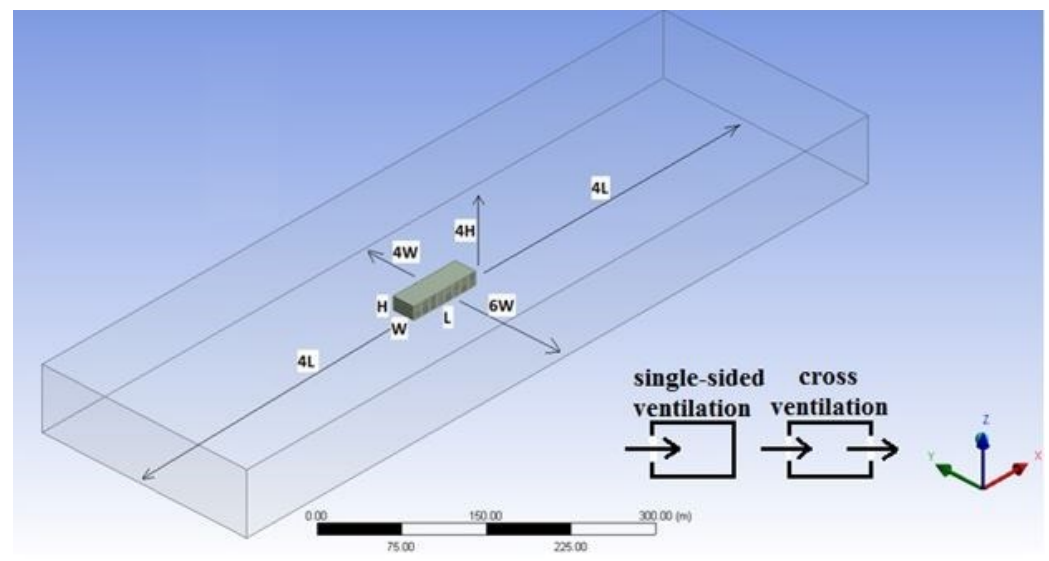

Figure 1. Schematic view of the model with outer domain (W: width, L: length and H: height).

\subsection{Evaluation approach}

To caculate annual NV hours and energy savings, an EXCEL VBA program is developed based on the evaluation method described above. The program input is the TMY3 hourly annual climate data which include the dry bulb temperature, atmospheric pressure, relative humidity, wind speed and wind direction. The output of the program is the NV potential hours. The developed program is then used for the evaluation of the NV hours in 50 US and 15 Canada cities. The output data are saved in the EXCEL file for generating a NV potential map of North America based on the GIS information of the cities.

The methodology for the development of coefficient selection guidance and evaluation method is summarized as the procedure a) $\sim \mathrm{f}$ ):

a) Choose building location, window facing, and weather data. Determine $f$ and $\Delta C_{p}$ from Fig. 5 (more detailed explanation will follow in section 3.2)

b) Choose type of terrain: open area, sub-urban, or urban, and determine $K$ and $\alpha$ from Table 1 to find the local wind velocity, $U$, from Eq. (3).

c) Choose the type of the window: casement, tilt, sliding window, and the value of $C_{D}$ can be determined from Table 2.

d) Enter other parameters, such as building size, window area etc.

e) Calculate airflow rates, $Q$, by Eq. (1) and/or Eq. (2), and indoor temperature, $T_{i}$, by Eq. (4) for a given indoor cooling load.

f) Count the annual total NV potential hours based on $T_{i}$ according to Eq. (5). 


\section{Results and discussion}

\subsection{Validation of CFD modelling method}

For the CFD simulations of building airflow, the two common turbulence models, RANS (Goubran et al., 2016; Lian et al., 2010) and Large Eddy Simulation (LES) (Qi et al., 2013), are often used. Therefore, in order to determine which model is more efficient and suitable in the current study, a validation study was undertaken using the experimental data from the literature (Jiang et al., 2003).

A series of boundary layer wind tunnel experiments have been conducted in Cardiff University by Jiang et al. (2003) to simulate an urban atmospheric environment by using blockages, fences and Lego Duplo blocks. A one-dimensional Laser Doppler Anemometer (LDA) with resolution of $\pm 0.05 \mathrm{~m} / \mathrm{s}$ was used to measure the velocity distribution. The model itself is a cubic block (250 $\mathrm{mm} \times 250 \mathrm{~mm} \times 250 \mathrm{~mm}$ ) as is shown in Fig. 2. For both windward and leeward single-sided NV cases, there is only one $84 \mathrm{~mm} \times 125 \mathrm{~mm}$ opening in one facade. Moreover, in case of cross ventilation, two openings with the same size are designed in opposite facades. The thickness of the walls was neglected since heat transfer is not considered in this validation study.

To validate the CFD modeling approach, the simulation results of the mean velocity distributions at five locations around and inside the building model were compared with the Jiang's wind tunnel test results. Both RANS (standard $k-\varepsilon$ model) and LES were used and the comparisons are shown in Fig. 3. The overall arrangement between the CFD predictions (RANS and LES) and experimental results is fairly similar along the streamline direction, which is close to the results from Jiang et al. (2003). The difference of the results between the two models are small at most of the locations. Thus, the RANS standard $k-\varepsilon$ model was selected to conduct the rest of simulations considering it is reasonably accurate and time-efficient comparing to the LES model.

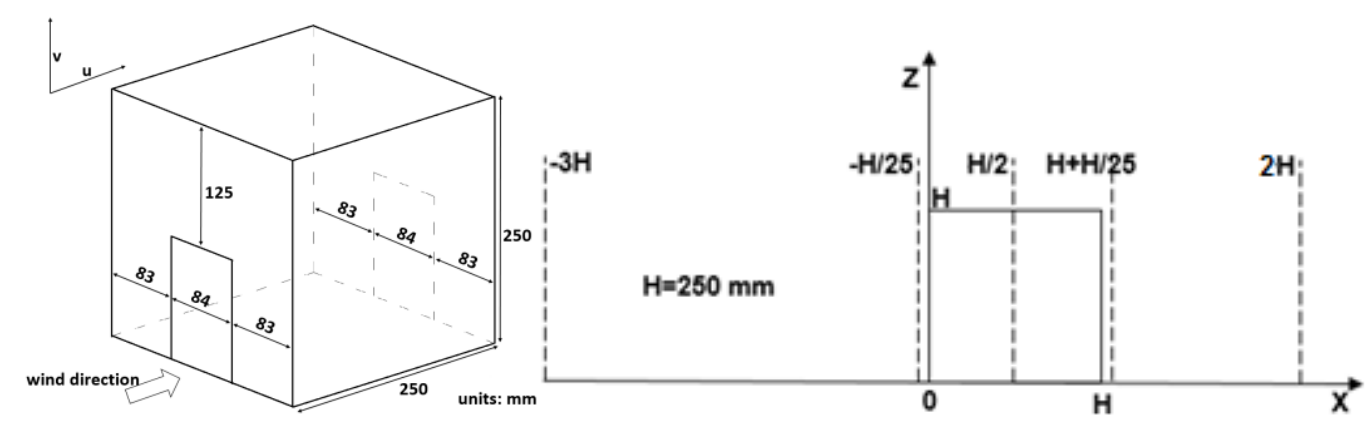

Figure 2. Schematic view of single-opening model and air velocity measurement locations. 


\section{- Experimental data -RANS model (Standard k-e model) --LES model}

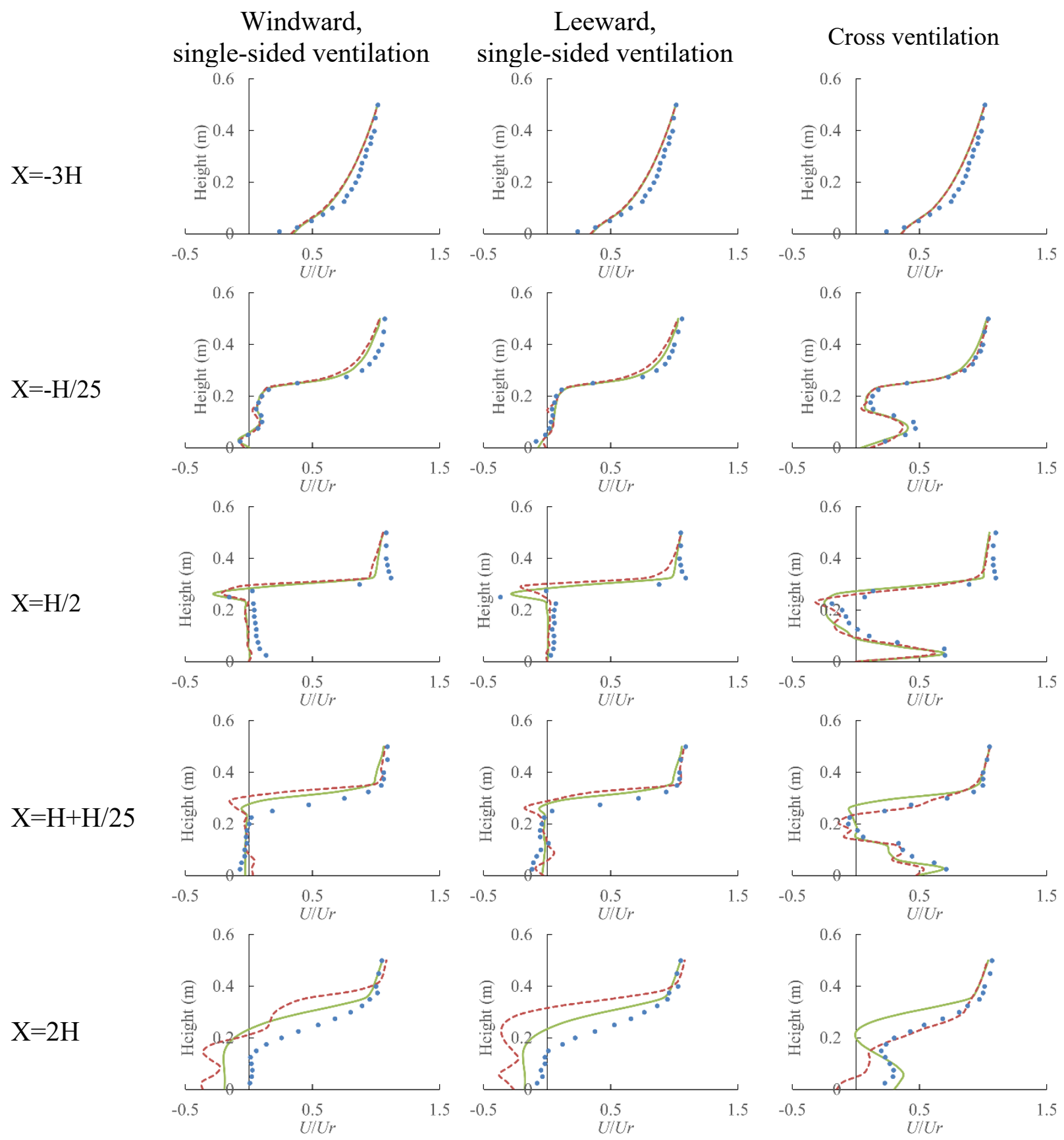

Figure 3. Comparison of mean velocity distributions between CFD simulation and experimental data (experimental data coming from the literature (Jiang et al., 2003)). 


\subsection{Critical ventilation coefficients}

To conduct the grid independence study, the cases with 0.5 million meshes and 1.4 million meshes were created for the two wind incidence angles $\theta$ of $45^{\circ}$ and $90^{\circ}$ for the building model in Fig. 1. Fig. 4 compares the NV airflow rates with different mesh resolutions and shows that the difference in airflow rates varies from $0.07 \%$ to $15 \%$, which is acceptable considering the difference in time consumption between the two scenarios. Therefore, all the other CFD simulation cases are with 0.5 million meshes.

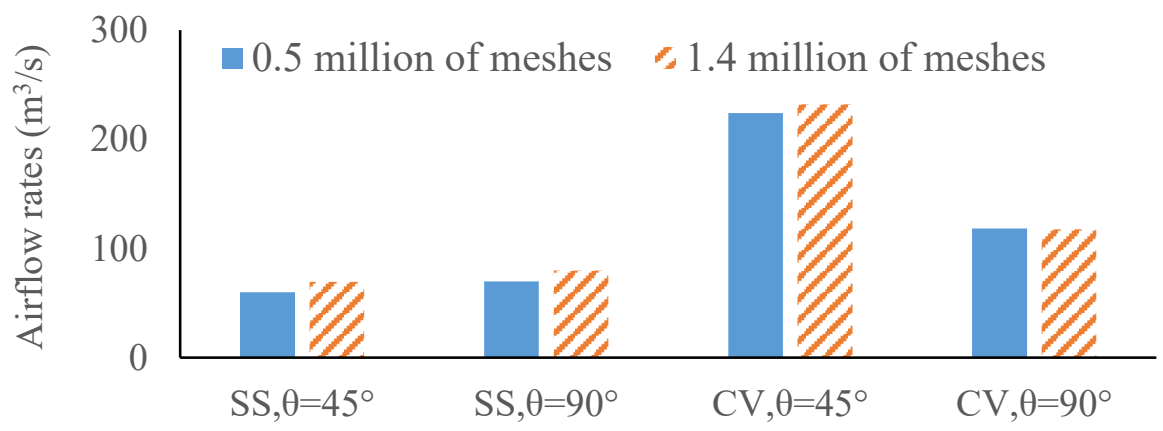

Figure 4. Grid independence study. SS: Single-sided ventilation; CV: Cross-ventilation.

Once the airflow rates for single-sided and cross-ventilation were acquired from the simulations for different numbers of building floors (i.e. three, four and five floors) at an interval of $15^{\circ}$ of wind incidence angle, the coefficients $f$ and $\Delta C_{p}$ were determined by using Eqs. (1) and (2). A total of $60 \mathrm{CFD}$ simulations were conducted and the critical ventilation coefficients are plotted in Fig. 5. Therefore, for given building parameters, ventilation types and weather information, e.g. single-side ventilation/cross-ventilation, number of floors and wind angle, the coefficients, $f$ or $\Delta C_{p}$, can be determined from Fig. 5. The NV airflow rate, $Q$, can be calculated using Eq. (1) or (2). Then the annual NV potential can be calculated by the evaluation approach in section 2.3. 

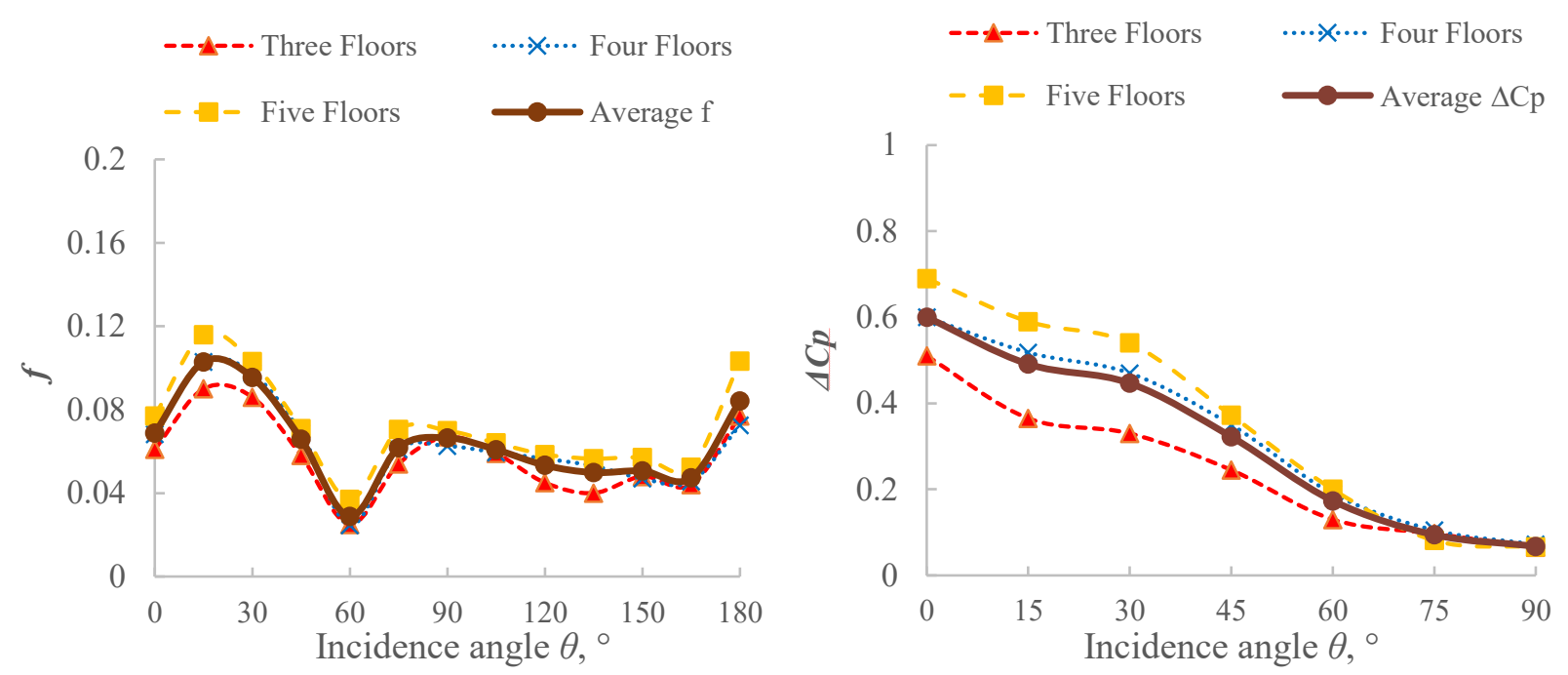

Figure 5. Coefficients $f$ for single-sided ventilation (left) and $\Delta C_{p}$ for cross-ventilation (right) under different scenarios.

\subsection{Case study}

The evaluation method presented in section 2.3 is capable of providing a fast energy saving potential analysis of $\mathrm{NV}$ for engineers and architects during the building early design stage. Although the critical ventilation coefficients are obtained from numerical simulations, which however are based on the validated CFD models and methodology of modeling NV in this case, the calculated NV potential is built upon justified facts and provide reasonably accurate information for guiding early building designs.

For demonstration, two four-story rectangular buildings with same dimension as the base model located in the open terrain of Toronto and Vancouver were chosen as a case study. Specifically, the indoor design temperature range, $T_{i}=21.5^{\circ} \mathrm{C} \sim 27.8^{\circ} \mathrm{C}$, is set to achieve $80 \%$ thermal comfort acceptability based on the Adaptive Model for naturally ventilated buildings (Brager and De Dear, 2000). This building is set to be an office building with a combined internal cooling load of 70 $\mathrm{W} / \mathrm{m}^{2}$ (CIBSE Guide A Steering Committee, 2015). Fig. 6 illustrates the annual NV available hours under both single-sided (SS) and cross natural ventilation (CV) scenarios for all different window facing directions. The optimal option can be clearly found. Specifically, the building in Toronto might achieve the maximum energy saving potential by using 1,644 hours of southwest facing single-sided NV. However, in Vancouver, only the building with northeast window could receive a total number of 1,460 annual NV available hours. The difference of number of hours 
between two cities might be due to Toronto having a higher average daily temperature from May to October, a period which is commonly believed as typical NV period for the past few decades (Government of Canada, 2018). When the cooling load, $C L$, is not high enough, a place with lower average daily temperature would get relatively lower $T_{i}$; in other words, it would result in fewer annual NV available hours. These numbers could be used to determine the viability of using NV and identify the optimum design during the conceptual design stage as a starting point for the later detailed energy saving analysis.

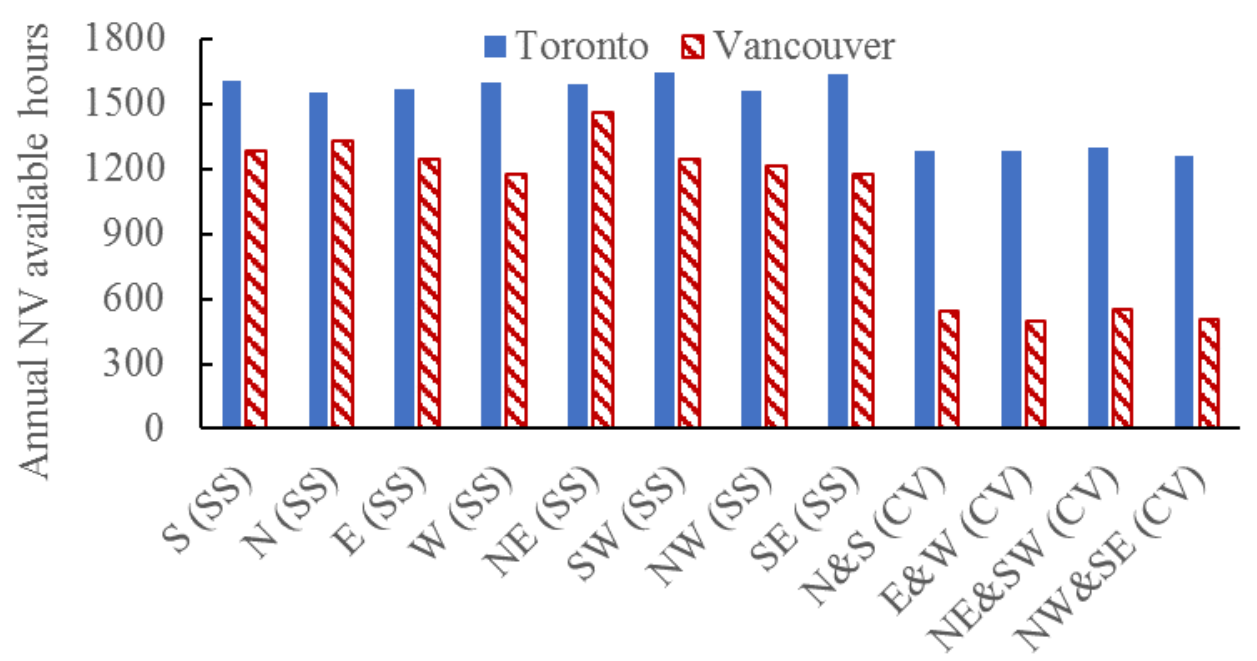

Window facing

Note: E: east, S: south, W: west, N: north, NE: northeast, SW: southwest, NW: northwest, SE: southeast (Figs. 6-9)

Figure 6. Annual natural ventilation potential in Toronto and Vancouver for an internal cooling load (heat gain) of $70 \mathrm{~W} / \mathrm{m}^{2}$.

Figures $7 \sim 9$ show the impact of window-wall ratio (WWR), window type and building terrain on energy savings for the building model in Toronto. Fig. 7 shows that a smaller WWR contributes to greater amount of energy saved (more NV potential): a WWR of 0.3 has about $5 \%$ more energy saving potential than $0.4 \mathrm{WWR}$ for the same building. This is consistent with requirement of the addendum to ASHRAE 189.1, "Standard for the Design of High-Performance, Green Buildings Except Low-Rise Residential Buildings" (ASHRAE, 2009), which proposes that the WWR should be decreased from $40 \%$ to $30 \%$ in order to reduce building energy consumption. Comparing with 
other type of windows (casement and tilt), the sliding windows could save up to $10 \%$ of energy as is shown in Fig. 8. Besides that, building terrain only makes apparent difference in cross ventilation as indicated in Fig. 9: in other words, the results show that building surrounding terrain has minimum impact on single-sided ventilation for the building studied, which is a quite interesting finding and worth a deeper investigation in the future.

Figures $7 \sim 9$ indicate that the scenario with a WWR of 0.3 (smallest WWR), sliding windows and an urban environment could contribute to the most annual NV potential hours. This scenario means a smaller opening area, a smaller $C_{D}$ (Table 2) and lower wind velocity (according to Eq. 3), which results in lower flow rate. The lower flow rate causes a higher temperature difference between indoor and outdoor, $\Delta T$, for constant internal cooling load, $C L$, as expressed in Eq. (4). Considering in Toronto, where the outdoor temperature is more likely lower than the lower limit of comfortable temperature range, $21.5^{\circ} \mathrm{C}$, lower flow rate will contribute to more annual NV available hours. The same scenario may not apply to other cities with different climate characteristics. Therefore, it is worthwhile to apply the current method to more cities, e.g. major cities in North America.

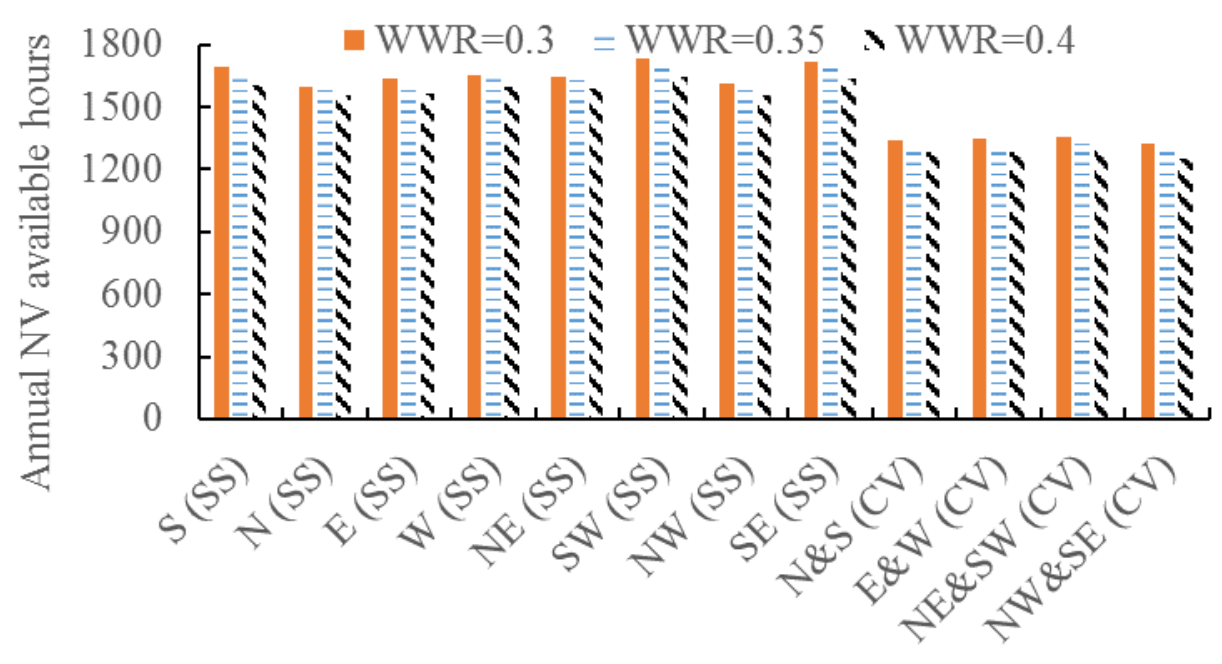

Window facing

Figure 7. Annual NV potentials under different window-wall ratio (WWR). 


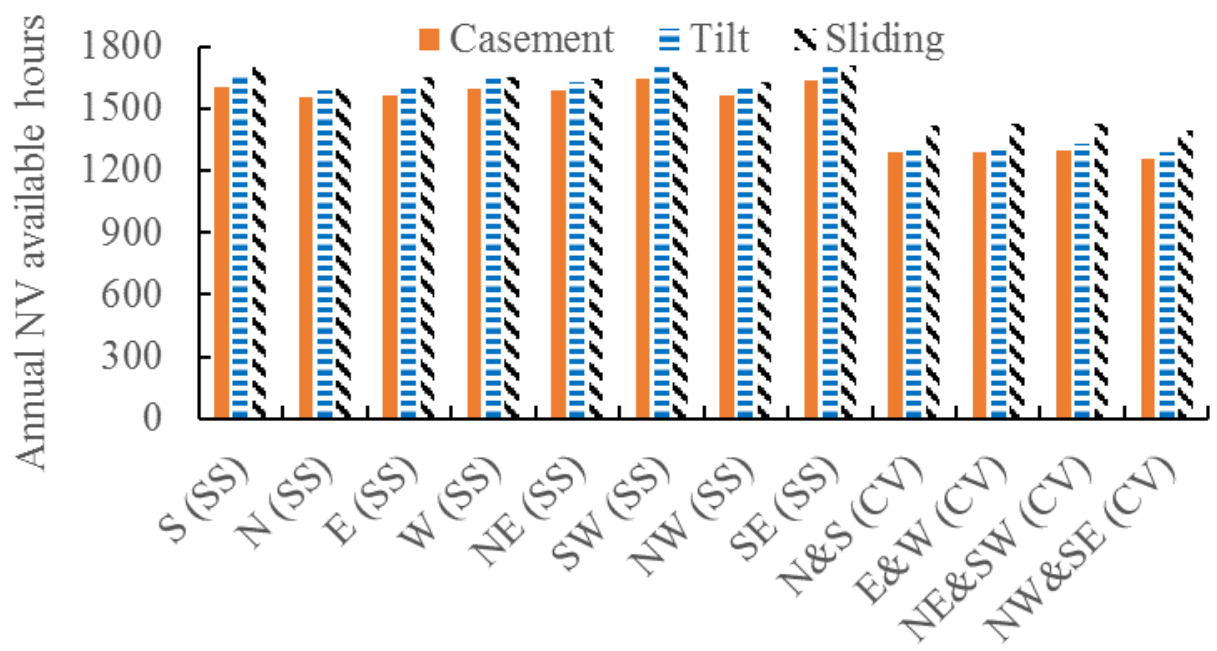

Window facing

Figure 8. Statics of annual NV available hours under different window type, WWR=0.3.

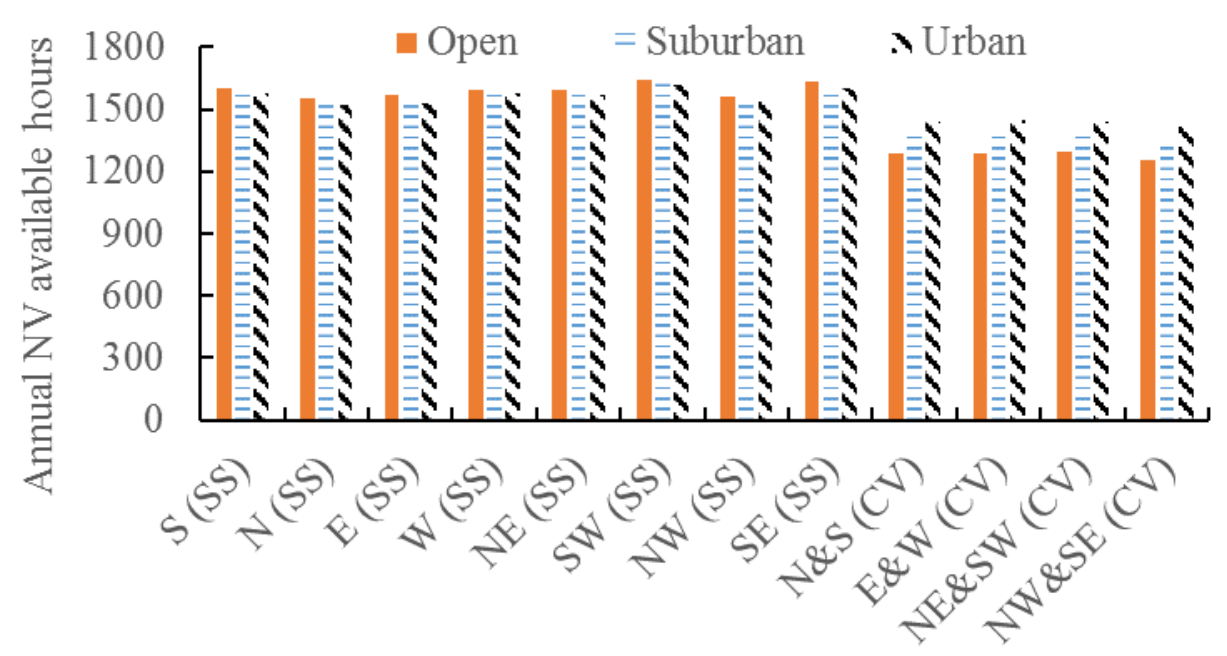

Window facing

Figure 9. Statics of annual NV available hours under different building terrain, WWR=0.3.

\subsection{Natural ventilation potential map of North America}

Natural ventilation potential depends on the local climate condition. In recent years, natural ventilation potential has been investigated around the world. Artmann et al. (2007) evaluated the potential for passive cooling of buildings by night-time ventilation all over Europe, creating the 
maps showing a high potential for night-time ventilation cooling over the whole of Northern Europe. Hiyama and Glicksman (2015) proposed the target air change rate as a criterion for quick performance evaluation of natural ventilation during early stages of building design, with maps of the target air change rate in the United States, which helps architects obtain a clear understanding of their design directions. Wang and Greenberg (2015) investigated the impact of window operation on building performance for different types of the ventilation system in three US cities with different climates. Tan and Deng (2017) investigated the natural ventilation potential of residential buildings in three most populous climate zones in Australia, which improves the understanding of natural ventilation potential in different climates. In this study, the proposed method is used to evaluate the natural ventilation potential of a simplified four-story rectangular building found anywhere in the North America.

Extending the previous case study to other cities in North America, the maximum annual total NV potential hours (i.e. among all parameters previously considered, e.g. window types, orientations, ventilation types etc.) can be obtained, and the maps of the natural ventilation potential could be developed. In this section, maps of the natural ventilation potential in the 50 cities of US and 15 cities of Canada are presented, which provide information for preliminary design stages. Buildings and other conditions are the same as the test case in section 3.4. The TMY3 hourly annual climatic data were used in this study as climate data. As a result, a total number of at least 14 million calculations will be needed for finding the critical ventilation coefficients (based on the cubic spline method if an interpolation is needed) and calculating the internal building temperature, $T_{i}$, which is almost impossible for an EXCEL VBA program. Therefore, we developed a new Clanguage GPU (graphical processing unit) computing program based on the NVIDIA CUDA library. The GPU program dramatically speed up the computing speed and we are able to generate all the data for plotting the GIS maps of NV potentials.

Figure 10 shows the maximum annual total NV potential hours across North America. The annual NV available hours under both single-sided (SS) and cross natural ventilation (CV) scenarios for all different window facing layouts are calculated for all cities to find the maximum value, and the corresponding window facing is then indicated by the arrow for each city as shown in Fig. 10. The GIS color map is then created using the cubic spline interpolation among the data of different cities to generate the smoother flooded contour map. 

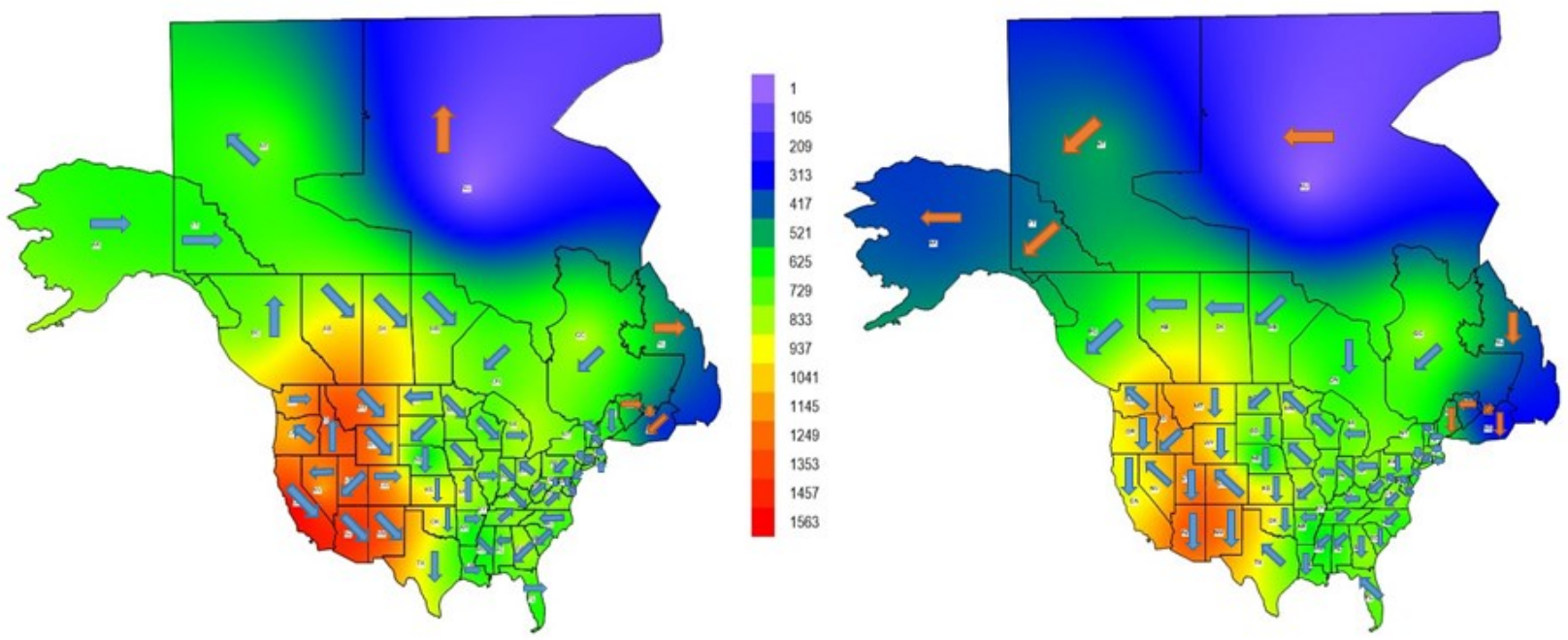

Figure 10. Maximum annual NV potentials (hours/year) across North America: single-sided (left), cross ventilation (right) for $70 \mathrm{~W} / \mathrm{m}^{2}$ internal cooling load.

As it can be seen for both scenarios, the most NV potential hours can be achieved in the cities with a moderate climate condition at the south-west of the US with a maximum value of 1,563 hours in California. The annual temperature variation of three cities located at different climate types are compared in Fig. 11 for Los Angeles (LA) in California with a moderate climate, Miami in Florida with a hot and humid climate, and Montreal in Quebec with a cold climate condition. It shows that in terms of the outdoor temperature applicable for NV as illustrated by the area falling within the banded range of $T_{\min }$ and $T_{\max }$, LA is the city with the most time of the year suitable for NV, even in the winter season. A more detailed comparison for different seasons is shown by Fig. 12 for these cities. The NV can rarely be used in summer days of Miami because of its hot and humid condition, and the summer potential hours of Montreal is even less than Los Angeles because Montreal weather is hot in the middle of the summer, whereas LA summers are warm and almost completely dry so NV can be used for most of summer days in LA. The winter potential hours of Montreal are much fewer than the other two cities because of the cold winters. Miami enjoys more NV potentials in the winter than that in LA because of its warmer winter days. In total, LA is with the most annual NV potential hours among all cities. Table 3 shows that single-sided ventilation is preferred in the mild climate of LA whereas it does not provide huge benefits over cross ventilation in the other two climates. This conclusion is also consistent with the color map in Fig. 10 where the major difference of benefit for single-sided ventilation is observed in the south west 
region of the US. There is also no apparent trend for the preferred window facing direction for both ventilation modes, which often depends on the local weather condition for each city.

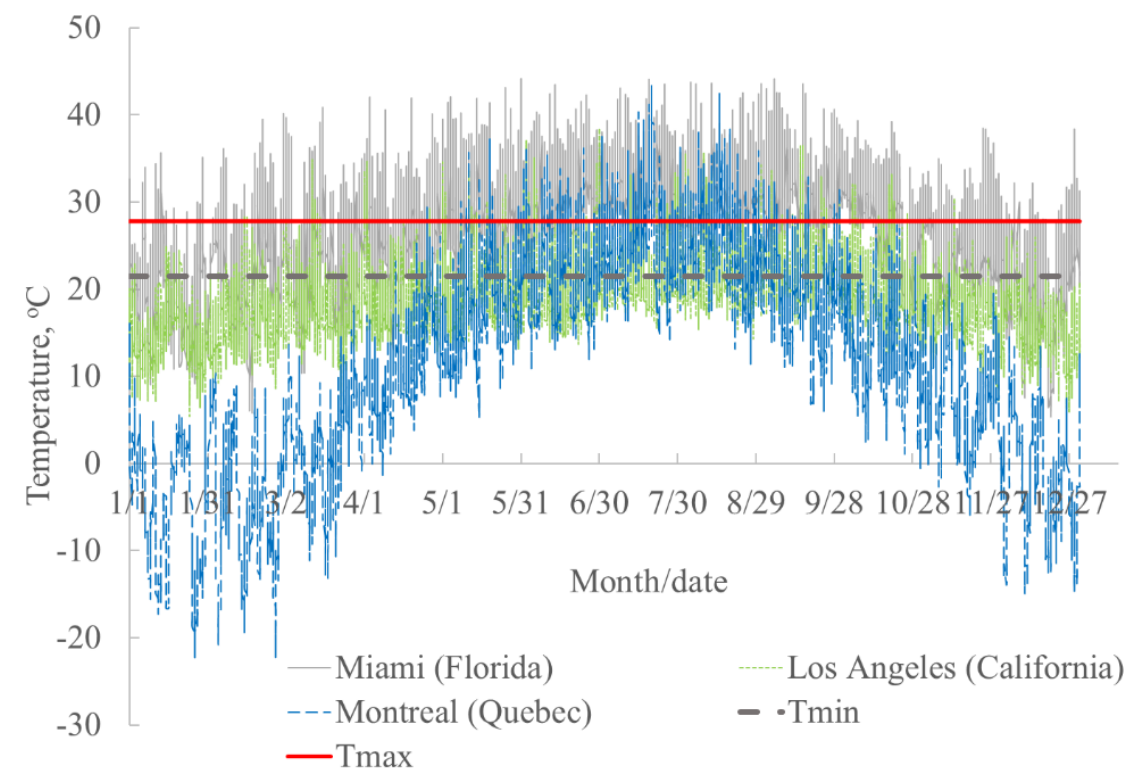

Figure 11. Comparison of annual ambient temperature of Miami (Florida), Los Angeles (California) and Montreal (Quebec) $\left(T_{\min }=21.5^{\circ} \mathrm{C}\right.$ and $\left.T_{\max }=27.8^{\circ} \mathrm{C}\right)$.

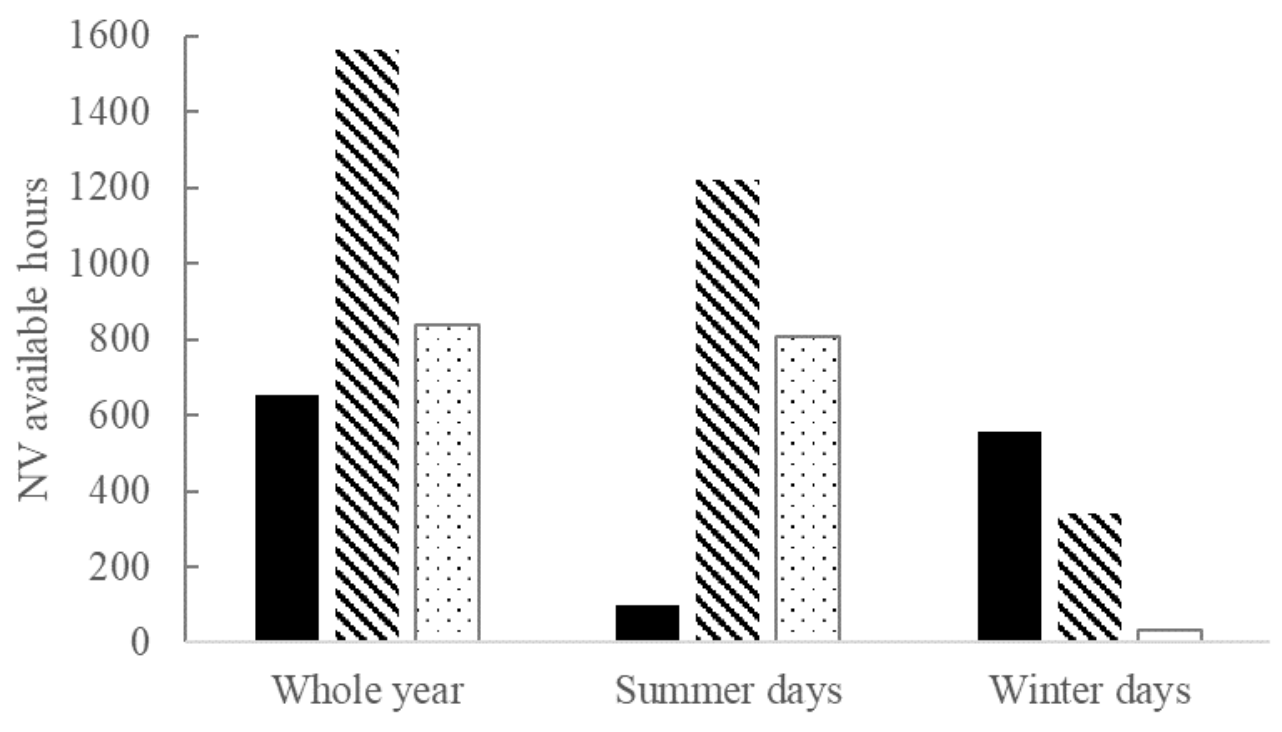

-Miami (Florida) `Los Angeles (California) ĐMontreal (Quebec)

Figure 12. Comparison of annual, summer days and winter days NV potential hours of Miami (Florida), Los Angeles (California) and Montreal (Quebec) for $70 \mathrm{~W} / \mathrm{m}^{2}$. 
Table 3. Comparison of annual NV potential hours of Los Angeles, Miami and Montreal for 70 $\mathrm{W} / \mathrm{m}^{2}$.

\begin{tabular}{ccc}
\hline \multirow{2}{*}{ City } & \multicolumn{2}{c}{$\begin{array}{c}\text { Annual NV } \\
\text { potential hours }\end{array}$} \\
\cline { 2 - 3 } & $\begin{array}{c}\text { Single- } \\
\text { sided }\end{array}$ & $\begin{array}{c}\text { Cross } \\
\text { ventilation }\end{array}$ \\
\hline Los Angeles & 1,563 & 927 \\
\hline Miami & 655 & 737 \\
\hline Montreal & 840 & 812 \\
\hline
\end{tabular}

Figure 13 shows the percentage of NV potential hours for the daytime (working time for office buildings), i.e., 9:00-17:00, for both single-sided and cross ventilation scenarios. The red color indicates more NV potential hours occur at the daytime working hours, whereas the purple color means that NV will be more utilized at the night time. Clearly, the maximum percentage of the daytime NV for both scenarios can be achieved from British Columbia, Canada (56\%) and the minimum percentage is at the Colorado, US (17\%). This means that more than half of the time of using NV will occur in the daytime for British Columbia, and for Colorado the nighttime NV will be more utilized than the daytime for the current case of investigation.
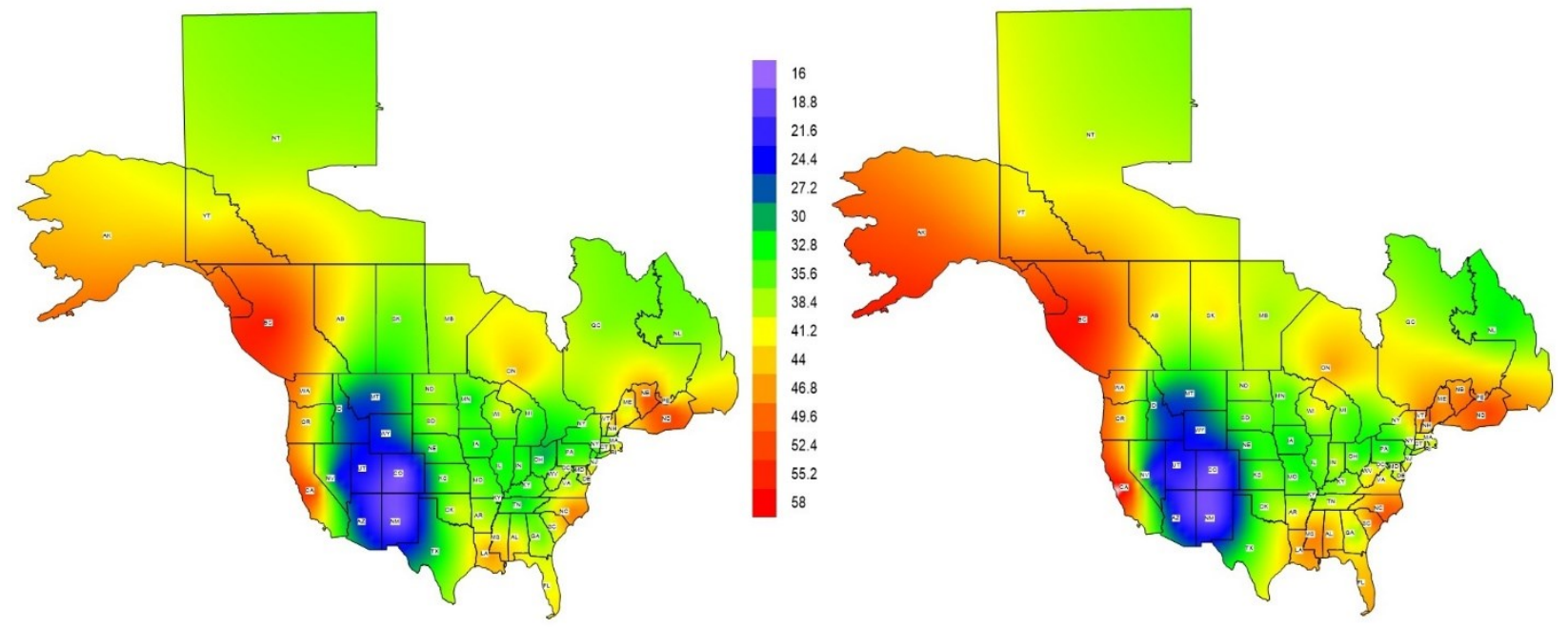

Figure 13. Daytime percentage of NV potential hours across North America: a) single-sided (left), b) cross ventilation (right) for $70 \mathrm{~W} / \mathrm{m}^{2}$. 


\section{Conclusions}

This paper explores the relationship between the critical ventilation coefficients (i.e. $f$ and $\Delta C_{p}$ ) and the key parameters such as wind incidence angles and building heights. With these ventilation coefficients found, a fast evaluation method in the form of empirical equations for the quick estimation of natural ventilation and energy saving potential was developed with the assistance from CFD simulations. During the building conceptual design phase, engineers and architects will be able to use this method to determine the viability and energy saving potential of NV in terms of ventilation strategies (single-sided or cross natural ventilation), building location (city and open terrain), building details (floor area, number of floors, etc.), opening details (window-to-wall ratio and window type), indoor design temperature range, and internal heat gains. Such early analysis and acquired information will provide them with justifiable facts to decide whether to invest a more detailed engineering analysis of a later stage, and with preliminary guidance to understand what the key parameters are, when applying and conducting more investigations on the $\mathrm{NV}$, so that the later engineering analysis will become more efficient and relatively easier.

Such benefits of the proposed method have been demonstrated in the case study. The Toronto NV analysis indicates that a building with a window-to-wall ratio of $30 \%$ has around $5 \%$ more natural ventilation energy saving potential than buildings with a window-to-wall ratio of $40 \%$ under both ventilation strategies, i.e. single-sided and cross-ventilation. Sliding windows were found to have up to $10 \%$ more natural ventilation energy saving potential than casement and tilt windows when other parameters were kept constant. Natural ventilation could also be used to save energy during transition season and winter, especially, in buildings with high internal heat gains such as hightech offices or data centers, which are more suitable with relatively lower summer and higher winter average daily temperatures to maximize energy savings from natural ventilation.

The evaluation approach is employed to evaluate the natural ventilation potentials across North America for both single-sided and cross ventilation scenarios. Thus, a series of natural ventilation potential maps were produced. These maps could improve the understanding of natural ventilation potential in different climates and benefit the climate-conscious design of buildings in North America. In addition, different values of cooling loads or heat gains corresponding to different building types can now be explored. The current method can also be expanded to study the NV 
potentials of the future under the impact of climate changes, such as the global warming, when the associated weather information is available.

\section{Acknowledgements}

The authors acknowledge the financial support from the Discovery Grants and the Engage Grants

of the Natural Sciences and Engineering Research Council of Canada (NSERC) [\# 402848-2012]

(2012 - 2018) and the Concordia University Research Chair (CURC) New Scholar (2014 - 2019).

\section{References}

Ai, Z.T., Mak, C.M., 2018. Wind-induced single-sided natural ventilation in buildings near a long street canyon: CFD evaluation of street configuration and envelope design. J. Wind Eng. Ind. Aerodyn. 172, 96-106.

Allard, F., Santamouris, M., 1998. Natural ventilation in buildings: a design handbook, in: London James James. p. 378.

Andersen, K.., Heiselberg, P., Aggerholm, S., 2002. Naturlig ventilation i erhvervsbygninger (in Danish). Statens byggeforskningsinstitut.

Artmann, N., Manz, H., Heiselberg, P., 2007. Climatic potential for passive cooling of buildings by night-time ventilation in Europe. Appl. Energy 84, 187-201.

https://doi.org/10.1016/j.apenergy.2006.05.004

ASHRAE, 2009. ASHRAE Standard 189.1-2009. Stand. Des. High-Performance Green Build. Except Low-Rise Resid. Build.

ASHRAE, 2004. ASHRAE Standard 55-2004, Thermal environmental conditions for human occupancy.

Brager, G.S., De Dear, R., 2000. A standard for natural ventilation. ASHRAE J. 42, 21-28. https://doi.org/10.1017/CBO9781107415324.004

Busch, J.F., 1992. A tale of two populations: thermal comfort in air-conditioned and naturally ventilated offices in Thailand. Energy Build. 18, 235-249. https://doi.org/10.1016/03787788(92)90016-A

Calautit, J.K., Hughes, B.R., 2014. Wind tunnel and CFD study of the natural ventilation performance of a commercial multi-directional wind tower. Build. Environ. 80, 71-83. https://doi.org/10.1016/j.buildenv.2014.05.022

Cao, S.-J., Kong, X.-R., Li, L., Zhang, W., Ye, Z.-P., Deng, Y., 2017. An investigation of the $\mathrm{PM}_{2.5}$ and $\mathrm{NO}_{2}$ concentrations and their human health impacts in the metro subway system 
of Suzhou, China. Environ. Sci. Process. Impacts 19, 666-675.

https://doi.org/10.1039/C6EM00655H

Chan, C.K., Yao, X., 2008. Air pollution in mega cities in China. Atmos. Environ. 42, 1-42. https://doi.org/10.1016/j.atmosenv.2007.09.003

Cheung, J.O.P., Liu, C.H., 2011. CFD simulations of natural ventilation behaviour in high-rise buildings in regular and staggered arrangements at various spacings. Energy Build. 43, 1149-1158. https://doi.org/10.1016/j.enbuild.2010.11.024

CIBSE Guide A Steering Committee, 2015. Guide A: Environmental design, 8th ed. Page Bros. (Norwich) Ltd, Norwich.

Cockroft, J.P., Robertson, P., 1976. Ventilation of an enclosure through a single opening. Build. Environ. 11, 29-35. https://doi.org/10.1016/0360-1323(76)90016-0

Collins, K.J., 1986. Low indoor temperatures and morbidity in the elderly. Age Ageing 15, 212 20.

Deng, H.-Y., Feng, Z., Cao, S.-J., 2017. Influence of air change rates on indoor CO 2 stratification in terms of Richardson number and vorticity. Build. Environ. 129, 74-84. https://doi.org/10.1016/j.buildenv.2017.12.009

Dubois, M.C., Blomsterberg, Å., 2011. Energy saving potential and strategies for electric lighting in future north european, low energy office buildings: A literature review. Energy Build. 43, 2572-2582. https://doi.org/10.1016/j.enbuild.2011.07.001

Gil-Baez, M., Barrios-Padura, Á., Molina-Huelva, M., Chacartegui, R., 2017. Natural ventilation systems in 21st-century for near zero energy school buildings. Energy 1-15. https://doi.org/10.1016/j.energy.2017.05.188

Goubran, S., Qi, D., Saleh, W.F.W.F., Wang, L., Zmeureanu, R., 2016. Experimental study on the flow characteristics of air curtains at building entrances. Build. Environ. 105, 225-235.

Government of Canada, 2018. Canadian Climate Normals 1981-2010 Station Data [WWW Document].

Gusten, J., Strindehag, O., 1995. Experiences of measures taken to improve the air quality in schools. Air Infiltration Rev. 16, 5-8.

Haghighat, F., Brohus, H., Rao, J., 2000. Modelling air infiltration due to wind fluctuations-a review. Build. Environ. 35, 377-385. https://doi.org/10.1016/S0360-1323(99)00028-1

Hiyama, K., Glicksman, L., 2015. Preliminary design method for naturally ventilated buildings using target air change rate and natural ventilation potential maps in the United States. Energy 89. https://doi.org/10.1016/j.energy.2015.06.026

Jiang, Y., Alexander, D., Jenkins, H., Arthur, R., Chen, Q., 2003. Natural ventilation in buildings: Measurement in a wind tunnel and numerical simulation with large-eddy simulation. J. Wind Eng. Ind. Aerodyn. 91, 331-353. https://doi.org/10.1016/S01676105(02)00380-X

Lee, S., Chang, M., 2000. Indoor and outdoor air quality investigation at schools in Hong Kong. 
Chemosphere 41, 109-113.

Lian, Z., Qi, D., Weiwei, L., 2010. Influence of indoor partition on air distribution of ceilingmounted cassette type indoor unit. J. Cent. South Univ. 41, 363-369.

Oropeza-Perez, I., Østergaard, P.A., 2014. The influence of an estimated energy saving due to natural ventilation on the Mexican energy system. Energy 64, 1080-1091. https://doi.org/10.1016/j.energy.2013.11.009

Qi, D., Wang, L., Zmeureanu, R., 2013. Large Eddy Simulation of Thermal Comfort and Energy Utilization Indices for Indoor Airflows 1-8.

Seppänen, O., Fisk, W.J., 2002. Association of ventilation system type with SBS symptoms in office workers. Indoor Air 12, 98-112. https://doi.org/10.1034/j.1600-0668.2002.01111.x

Stabile, L., Dell'Isola, M., Russi, A., Massimo, A., Buonanno, G., 2016. The effect of natural ventilation strategy on indoor air quality in schools.

Tan, Z., Deng, X., 2017. Assessment of Natural Ventilation Potential for Residential Buildings across Different Climate Zones in Australia. Atmosphere (Basel). 8, 177. https://doi.org/10.3390/atmos8090177

Tominaga, Y., Stathopoulos, T., 2011. CFD modeling of pollution dispersion in a street canyon: Comparison between LES and RANS. J. Wind Eng. Ind. Aerodyn. 99, 340-348. https://doi.org/10.1016/j.jweia.2010.12.005

Tong, Z., Chen, Y., Malkawai, A., Liu, Z., Freeman, R., 2016. Energy saving potential of natural ventilation in China: the impact of ambient air pollution. Appl. Energy 179, 660-668.

Tzempelikos, A., Athienitis, A.K., 2007. The impact of shading design and control on building cooling and lighting demand. Sol. Energy 81, 369-382.

https://doi.org/10.1016/j.solener.2006.06.015

Wang, H., Chen, Q., 2012. A new empirical model for predicting single-sided, wind-driven natural ventilation in buildings. Energy Build. 54, 386-394.

https://doi.org/10.1016/j.enbuild.2012.07.028

Wang, L., Greenberg, S., 2015. Window operation and impacts on building energy consumption. Energy Build. 92, 313-321. https://doi.org/10.1016/j.enbuild.2015.01.060

Wang, L., Pan, Y., Huang, Z., 2012. Factors Affecting Discharge Coefficient of Building Ventilation Windows (in Chinese). Build. Energy Effic. 40.

Zhou, Y., Deng, Y., Wu, P., Cao, S.J., 2017. The effects of ventilation and floor heating systems on the dispersion and deposition of fine particles in an enclosed environment. Build. Environ. 125, 192-205. https://doi.org/10.1016/j.buildenv.2017.08.049 